Article

\title{
Preparation and Morphology Studies of Nano Zinc Oxide Obtained Using Native and Modified Chitosans
}

\author{
Munusamy Thirumavalavan, Kai-Lin Huang and Jiunn-Fwu Lee * \\ Graduate Institute of Environmental Engineering, National Central University, Chung-Li, Taoyuan \\ County, 320, Taiwan; E-Mails: mtvala@yahoo.com (M.T.); kuroleo@msn.com (K.-L.H.) \\ * Author to whom correspondence should be addressed: E-Mail: jflee@ ncuen.ncu.edu.tw; \\ Tel.: +886-3-4227151-34658; Fax: +886-3-4226742.
}

Received: 17 July 2013; in revised form: 26 August 2013 / Accepted: 16 September 2013 / Published: 18 September 2013

\begin{abstract}
Nano zinc oxide $(\mathrm{ZnO})$ with moderate surface area and high pore volume were prepared using a facile preparation method. Chitosan was utilized as both chelating and structure directing agent. The application of chitosans in this study suggested that even biowastes can be served in a productive manner economically. The surface modification of chitosan was carried out in order to increase the interaction between chitosan and zinc ions. The effect of sodium chloroacetate and isopropyl alcohol on the surface modification process was also explored. FT-IR (Fourier transform-infrared spectrometer) and TGA (Thermogravimetric analyses) analyses revealed that modified chitosans are more stable than those of unmodified chitosan. Among surface modified chitosans, CMC1 (1.5 M sodium chloroacetate and 75\% isopropyl alcohol) showed enhanced surface properties. Freundlich adsorption isotherms as preliminary studies confirmed that modified chitosan showed enhanced interaction with zinc ions. The interaction of zinc salt with chitosans produced a zinc-chitosan polymer. This finally cleaved upon calcination to produce nano $\mathrm{ZnO}$. The effects of different calcination temperatures indicated that $450{ }^{\circ} \mathrm{C}$ is the optimum calcination temperature to produce the nano $\mathrm{ZnO}$ with favored surface area $\left(15.45 \mathrm{~m}^{2} / \mathrm{g}\right)$ and pore size $(221.40 \mathrm{~nm})$. SEM (Scanning electron microscope) and TEM (Transmission electron microscope) of $\mathrm{ZnO}$ indicated that uniform particle and shape distributions were obtained at low calcination temperature $\left(450{ }^{\circ} \mathrm{C}\right)$.
\end{abstract}

Key words: chitosans; modification; nano ZnO; SEM; BET 


\section{Introduction}

Zinc oxide $(\mathrm{ZnO})$ has considerable customary attention due to its unique morphology and dimension-dependent optoelectronic properties [1]. It has special properties, such as high chemical activity, and novel optical, mechanical, electromagnetic, thermodynamic and electrodynamic properties, and displays a wide spectrum of applications, including gaseous sensors [2], fluorescent materials [3], photocatalysts [4], and additives in many industrial products [5]. Furthermore, $\mathrm{ZnO}$ is an environmentally friendly material, which is desirable especially for bio-applications, such as bio-imaging and cancer detection [6]. Several physical and chemical methods have been developed to obtain $\mathrm{ZnO}$ micro- and nanoparticles with different shapes. Various strategies such as chemical vapor deposition [7,8], electrochemical deposition [9-11], hydrothermal solution synthesis [12-14], and sol-gel processing [15] have been developed for the synthesis of $\mathrm{ZnO}$ nano materials. The sol-gel process and hydrothermal synthesis have proved to be relatively simple methods for synthesizing $\mathrm{ZnO}$ nanoparticles with a narrow size distribution and excellent crystallinity [16,17]. However, the organic materials utilized in the process make controlling of aggregation and large-scale production quite impossible. Various nanostructures in terms of shape and size have been found to hold novel applications depending upon on their morphologies and also the precursors [18-21]. Though various methods have been explored for synthesis of $\mathrm{ZnO}$ nanoparticles, we have developed a simple method, which involves the phenomenon of complex formation between metal ions and polysaccharides. Polysaccharides as stabilizing agents in this present task, met the requirement for the needs of cheap and renewable raw materials. Much of today's research has further indicated that the capture of metal ions by forming complexes with polysaccharides has been used in the sequestration or removal of metal ions, solvent extraction, dyeing, catalysis, water treatment, and many other industrial processes [22]. It has also been realized [23], in recent years that the mechanism of complex formation of metals with polysaccharides is manifold and probably dominated by different processes taking place simultaneously, such as adsorption, ion-exchange, and chelation, under different conditions. Until now many methods have been developed to synthesize zinc oxide nanocrystals dispersed onto various supported materials. The common disadvantages of this method include the wide distribution of particle diameter, as well as the expensive raw materials. However, the use of metal-organic supramolecular compounds as precursors for the preparation of inorganic nanomaterials, such as $\mathrm{ZnO}$, has not yet been thoroughly investigated.

This study attempts to take advantage of interaction between alkaline polysaccharides (both native and modified chitosans) and zinc metal salts to prepare nano $\mathrm{ZnO}$. Generally, polysaccharides contain hydroxyl, and amino functional groups, which can form chelation with $\mathrm{Zn}$ metals by chemical adsorption. Finally calcination resulted into the cleavage of Zn-polysaccharides chelate to form nano $\mathrm{ZnO}$. These polysaccharides in this study can effectively act as both chelating and structure directing agents. To enhance the degree of complexation of $\mathrm{Zn}$ metal and polysaccharides, necessary surface modification shave been carried out in this study. The effects of reaction temperature, concentration of solvents, and concentration of reactants were also studied during surface modification. The adsorption efficiency of these chitosans towards zinc metal was also explored in this study using Freundlich adsorption isotherms. The cheap, high stability, low toxicity, and environmentally friendly features of 
these polysaccharides along with simple and convenient technology have enabled to obtain nano $\mathrm{ZnO}$ in this present investigation.

The objective of this investigation was to emphasize the significant application of low cost biowastes (chitosans) for the effective production of nanomaterials and also to elucidate the formation of coordinate linkages and the surface microstructure when $\mathrm{Zn}^{2+}$ ion complexes with native and surface modified chitosan under specific conditions. In the present work, the effects of the different reaction conditions on particle size, and morphology were studied and the surface properties of various nano $\mathrm{ZnO}$ obtained from different chitosans were compared.

\section{Experimental}

\subsection{Chemicals}

Deionized distilled water was used to prepare all solutions. Standard metal ion solution, Zinc nitrate hexahydrate $\left[\mathrm{Zn}\left(\mathrm{NO}_{3}\right)_{2} \cdot 6 \mathrm{H}_{2} \mathrm{O}\right]$ was commercially obtained from J.T. Baker. Low molecular weight chitosan (molecular weight: $140 \mathrm{kDa}$ ) was obtained commercially from Aldrich. All the chemicals and reagents used in this study were of analytical grade and used without any further purification.

\subsection{Chemical Modification of Chitosan}

Chemically-modified chitosan was prepared according to the modified methods [24,25] by alkalization and etherification. The reaction parameters, such as concentrations of isopropyl alcohol and sodium chloroacetate, were varied to obtain a variety of modified chitosans. Ten grams (10 g) of chitosan powder was dispersed in $100 \mathrm{~mL}$ of different concentration ratio (75\% and 50\%) of isopropyl alcohol and stirred at $28{ }^{\circ} \mathrm{C}$ for $30 \mathrm{~min}$. A solution of $25 \mathrm{~mL} 10 \mathrm{M}$ sodium hydroxide was added in five equal portions over $25 \mathrm{~min}$ (at an interval of $5 \mathrm{~min}$ ) under stirring and continued to stir for additional 30 min. Following this, different concentrations (1.5, 2.25 and $3 \mathrm{M}$ ) of sodium chloroacetate dissolved in $45 \mathrm{~mL} 10 \mathrm{~N}$ sodium hydroxide and small amount of water were added to the mixture. Following this, the reaction mixture was stirred for $3 \mathrm{~h}$ at $60^{\circ} \mathrm{C}$. The resultant solution was filtered and washed with ethanol for three times, then dried in an oven at $60{ }^{\circ} \mathrm{C}$ for one day to get modified chitosan. Chitosan was referred to as CTS. Chemically modified chitosans prepared using 1.5, 2.25, and $3 \mathrm{M}$ sodium chloroacetate with $75 \%$ isopropyl alcohol were referred to as CMC1, CMC2, and CMC3 respectively. Chemically modified chitosans prepared using 1.5, 2.25, and $3 \mathrm{M}$ sodium chloroacetate with 50\% isopropyl alcohol were referred to as CMC4, CMC5, and CMC6 respectively.

\subsection{Adsorption Studies}

In order to understand the affinity of native and modified chitosan towards zinc metal ions, adsorption experiment was carried out as a primary study and fitted with Freundlich isotherm model.

The adsorption of $\mathrm{Zn}^{2+}$ was investigated in batch equilibrium experiments using zinc nitrate solution. The experiments were performed in $25 \mathrm{~mL}$ centrifuge bottle by stirring $25 \mathrm{~mL}$ zinc ion solution and $0.1 \mathrm{~g}$ of the adsorbents (native and surface modified chitosan) at $130 \mathrm{rpm}$ in a Lab-line orbit environ shaker for $24 \mathrm{~h}$. The temperature was maintained at $28{ }^{\circ} \mathrm{C}$. The adsorption of metal ions from the aqueous solutions was studied. After the desired reaction period, the aqueous phases were 
separated from the materials by centrifugation at $4500 \mathrm{rpm}$ for $5 \mathrm{~min}$ and the concentration of metal ions was measured using an AA-400 atomic absorption spectrophotometer (AAS, Varian, Inc., Palo Alto, CA, USA).

\subsection{Synthesis of ZnO Using Native and Surface Modified Chitosan}

Three gram of zinc nitrate hexahydrate $\left[\mathrm{Zn}\left(\mathrm{NO}_{3}\right)_{2} \cdot 6 \mathrm{H}_{2} \mathrm{O}\right]$ was dissolved in $100 \mathrm{~mL}$ water in a standard flask. To this zinc nitrate aqueous solution, $3 \mathrm{~g}$ of native and surface modified chitosan was added respectively and the reaction mixture was stirred constantly at $28{ }^{\circ} \mathrm{C}$ for $6 \mathrm{~h}$. Following this, the reaction mixture was filtered and the solid collected was dried in an oven at $50{ }^{\circ} \mathrm{C}$ to obtain zinc-chitosan organic polymers. Finally this zinc-chitosan organic polymer was calcined at three different temperatures, namely 450, 650, and $860{ }^{\circ} \mathrm{C}$, to obtain $\mathrm{ZnO}$ nanostructures such as $\mathrm{ZnO}-\mathrm{CTS}$ (from CTS), ZnO-CMC1 (from CMC1), ZnO-CMC2 (from CMC2), ZnO-CMC3 (from CMC3), ZnO-CMC4 (from CMC4), ZnO-CMC5 (from CMC5), and ZnO-CMC6 (from CMC6) with various morphologies. $\mathrm{ZnO}$ samples obtained from various systems were referred as shown in Table 1.

Table 1. $\mathrm{ZnO}$ prepared from various systems.

\begin{tabular}{|c|c|c|c|}
\hline \multirow[t]{2}{*}{ Precursors } & \multicolumn{3}{|c|}{$\begin{array}{c}\mathrm{ZnO} \text { samples prepared at various calcination } \\
\text { temperatures of } \mathrm{Zn} \text {-chitosan polymers }\end{array}$} \\
\hline & $450^{\circ} \mathrm{C}$ & $650^{\circ} \mathrm{C}$ & $850^{\circ} \mathrm{C}$ \\
\hline CTS & ZnO-CTS-450 & $\mathrm{ZnO}-\mathrm{CTS}-650$ & ZnO-CTS-850 \\
\hline $\mathrm{CMC1}$ & $\mathrm{ZnO}-\mathrm{CMC} 1-450$ & $\mathrm{ZnO}-\mathrm{CMC1-650}$ & $\mathrm{ZnO}-\mathrm{CMC} 1-850$ \\
\hline $\mathrm{CMC2}$ & $\mathrm{ZnO}-\mathrm{CMC} 2-450$ & $\mathrm{ZnO}-\mathrm{CMC} 2-650$ & $\mathrm{ZnO}-\mathrm{CMC} 2-850$ \\
\hline CMC3 & $\mathrm{ZnO}-\mathrm{CMC} 3-450$ & $\mathrm{ZnO}-\mathrm{CMC} 3-650$ & $\mathrm{ZnO}-\mathrm{CMC} 3-850$ \\
\hline CMC4 & $\mathrm{ZnO}-\mathrm{CMC} 4-450$ & $\mathrm{ZnO}-\mathrm{CMC} 4-650$ & $\mathrm{ZnO}-\mathrm{CMC} 4-850$ \\
\hline CMC5 & $\mathrm{ZnO}-\mathrm{CMC5}-450$ & $\mathrm{ZnO}-\mathrm{CMC5}-650$ & $\mathrm{ZnO}-\mathrm{CMC} 5-850$ \\
\hline CMC6 & ZnO-CMC6-450 & $\mathrm{ZnO-CMC6-650}$ & ZnO-CMC6-850 \\
\hline
\end{tabular}

\subsection{Characterization Techniques}

The average pore diameter and specific surface area [BET (Brunauer-Emmett-Teller) surface and pore volume] were measured on a Quantochrome NOVA 1000 (Boynton Beach, FL, USA). XRD patterns were obtained at room temperature using a Bruker KAPPA APEX II instrument (Billerica, MA, USA). Scanning electron microscope SEM study was carried out on an HITACHI-S-800, field emission scanning electron microscope. TEM study was carried out on a transmission electron microscopy (JEM-2010type). FT-IR spectra were obtained on a Neclit 6700 model, FTIR. TGA was performed with Universal V4.4A (TA Instruments, New Castle, DE, USA).

\section{Results and Discussion}

\subsection{Characterization of Native and Surface Modified Chitosans}

The functional groups present in chitosan and modified chitosan were identified using FT-IR technique. Figure 1 shows the FT-IR spectra of native and surface modified chitosans. The peak [26] around $3480 \mathrm{~cm}^{-1}$, is due to $v(\mathrm{O}-\mathrm{H})$, the peak at 2800 to $3000 \mathrm{~cm}^{-1}$ is due to $v\left(\mathrm{CH}_{3}, \mathrm{CH}_{2}, \mathrm{CH}\right.$, and 
$\mathrm{NH})$, the peak at 1630 to $1650 \mathrm{~cm}^{-1}$ is due to $v(\mathrm{C}=\mathrm{O})$, the peak around 1400 to $1500 \mathrm{~cm}^{-1}$ is due to $v(\mathrm{CO})$ deformation from alcoholic and phenolic and symmetric $v(\mathrm{COO})$ and the peak at 1050 to $1300 \mathrm{~cm}^{-1}$ is due to $v(\mathrm{C}-\mathrm{O})$ of chitosan. It can be seen from Figure 1 that the broadness of the peak around $3480 \mathrm{~cm}^{-1}$ is gradually diminished upon surface modification, which indicates the decrease of water and enhancement of carboxylic functional groups in chitosan. In addition, significant increase of $\mathrm{C}=\mathrm{O}$ peak intensity around 1630 to $1650 \mathrm{~cm}^{-1}$ confirms the higher degree of carboxylic group of modified chitosan. It is connoted that the intensity [27] of $v(\mathrm{O}-\mathrm{H})$ and $v(\mathrm{C}=\mathrm{O})$ was significantly affected by the factors such as concentrations of sodium chloroacetate and isopropyl alcohol. It is observed when concentration of sodium chloroacetate increased the intensity and peak width of FT-IR spectra of modified chitosan around 1630 to $1650 \mathrm{~cm}^{-1}$ also increased significantly. Despite the increase in $v(\mathrm{C}=\mathrm{O})$, the intensity of peak around 1400 to $1500 \mathrm{~cm}^{-1}$ also increased definitely. This clearly evidenced that, at higher concentration of sodium chloroacetate, the deformation of $\mathrm{C}=\mathrm{O}$ enhanced and the free $\mathrm{COO}^{-}$on chitosan surface is diminished.

Figure 1. FT-IR spectra of native and modified chitosans.

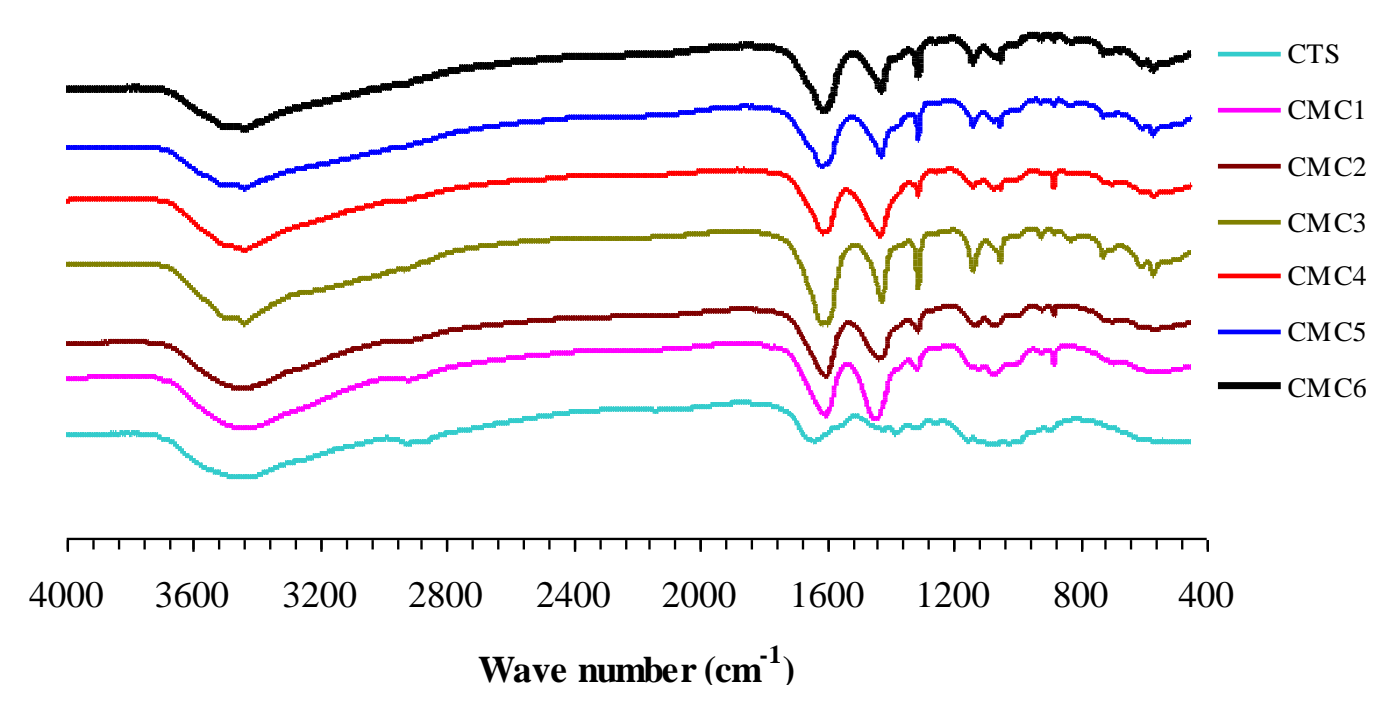

There will be no significant change in the $\mathrm{NH}_{2}$ peak upon coordination with metal ions and, moreover, making the differentiation is also not always possible. It is expected that the carboxyl groups of the chitosan can interact with zinc metal to form chitosan-zinc complexes. In general, the un-ionized and uncoordinated carboxylic acid $(\mathrm{C}=\mathrm{O})$ stretching band occurs at $1700-1750 \mathrm{~cm}^{-1}$, whereas the ionized and coordinated stretching band occurs at $1650-1590 \mathrm{~cm}^{-1}$. In this study, no absorption band in the region of $1700-1750 \mathrm{~cm}^{-1}$ was observed, indicating that the carboxyl groups have a high degree of an ionic characteristic. The ionized carbonyl frequencies in chelating samples suggest that the chelation of chitosan with $\mathrm{Zn}^{2+}$ occurred in the ionized moiety of the carboxyl groups. Thermogravimetric analyses of the zinc-chitosans organic polymers using native and surface modified chitosan were conducted from room temperature (RT) to $900{ }^{\circ} \mathrm{C}$. The TGA and DTA curves for a typical precursor are shown in Figure 2. The weight loss curves of the native chitosan in the range 200-450 ${ }^{\circ} \mathrm{C}$ are associated with the decomposition of chitosan [28]. The corresponding weight loss curves of the modified chitosans, in the range $200-700{ }^{\circ} \mathrm{C}$, imply the multiple weight loss events of modified chitosan. The residual weight (remaining) of chitosans during TGA analysis is tabulated in 
Table 2. From Table 2, it is seen that the residual weight of modified chitosans after various pyrolysis temperatures is more than that of native chitosan indicating that the modified chitosans are more stable [25] than those of native chitosan. Among all, CMC1 has more residual weight after TGA and thus considered to be the most stable chitosan in this study. A systematic correlation study carried out between two different concentrations (75\% and 50\%) of isopropyl alcohol revealed that for the same system with $75 \%$ isopropyl alcohol, the corresponding weight loss is lower than that of 50\% isopropyl alcohol. This is due to the fact that the water puffing extent of 50\% isopropyl system is greater than that of 75\% isopropyl system. Thus the larger weight loss is accompanied with 50\% isopropyl alcohol. Table 2, clearly conveyed that there is no obvious correlation between different concentrations of sodium chloroacetate.

Table 2. Residual weight of zinc-chitosans organic polymers during TGA after different pyrolysis temperatures.

\begin{tabular}{cccc}
\hline \multirow{2}{*}{ Precursors } & \multicolumn{3}{c}{ Residual weight $(\%)$ of precursors after pyrolysis } \\
\cline { 2 - 4 } & $\mathbf{4 5 0}{ }^{\circ} \mathbf{C}$ & $\mathbf{6 5 0}^{\circ} \mathbf{C}$ & $\mathbf{8 5 0}{ }^{\circ} \mathbf{C}$ \\
\hline CTS & 34.05 & 11.45 & 11.40 \\
$\mathrm{CMC} 1$ & 53.11 & 36.80 & 32.02 \\
$\mathrm{CMC} 2$ & 48.94 & 29.61 & 25.10 \\
$\mathrm{CMC} 3$ & 52.92 & 34.05 & 30.89 \\
$\mathrm{CMC} 4$ & 31.66 & 23.92 & 23.00 \\
$\mathrm{CMC5}$ & 42.52 & 20.87 & 19.99 \\
$\mathrm{CMC6}$ & 41.56 & 15.49 & 15.42 \\
\hline
\end{tabular}

Figure 2. TGA and DTA curves for zinc-chitosans organic polymers using (a) CTS; (b) $\mathrm{CMC} 1$; and (c) CMC4.

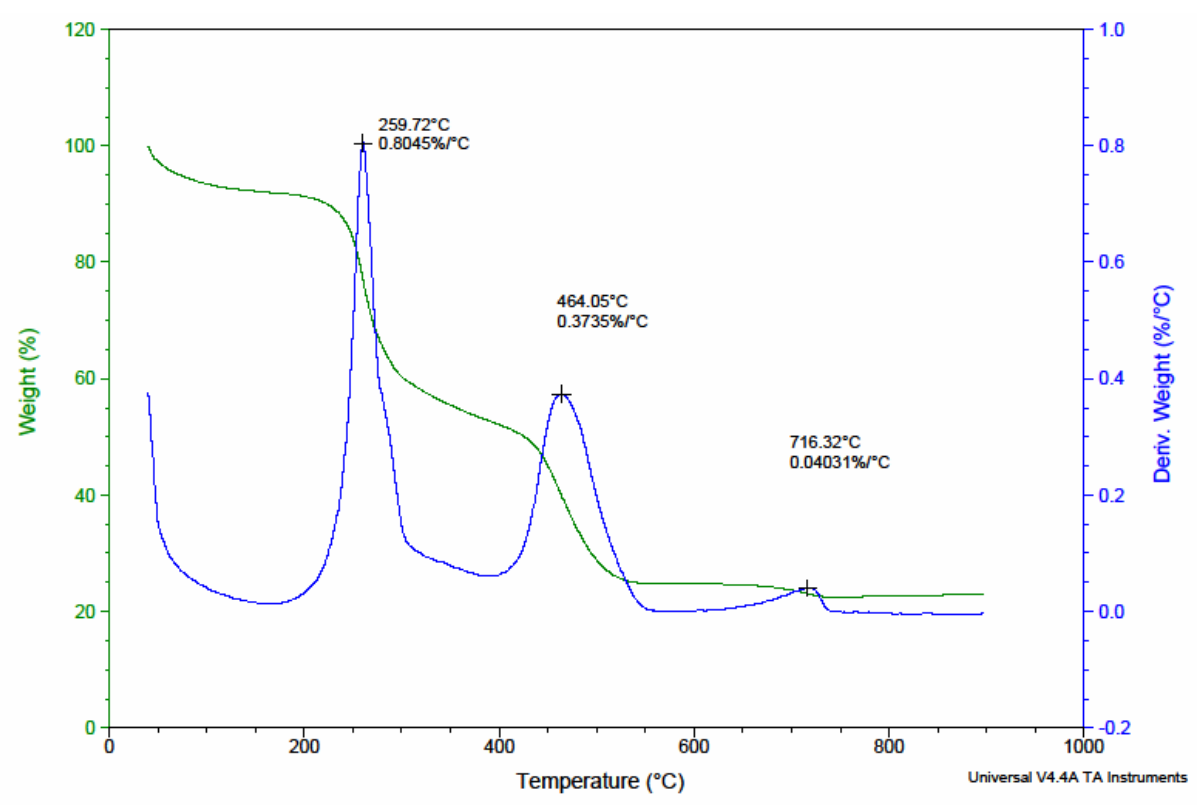

(a) 
Figure 2. Cont.

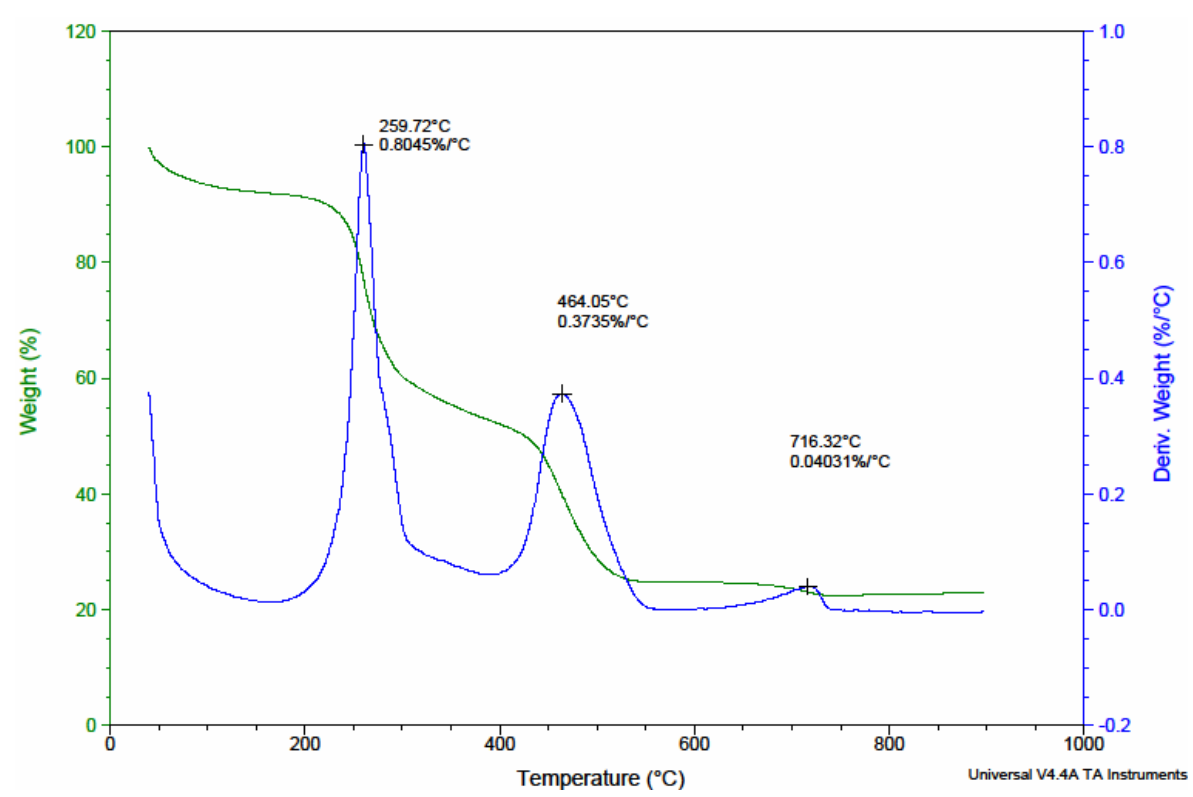

(b)

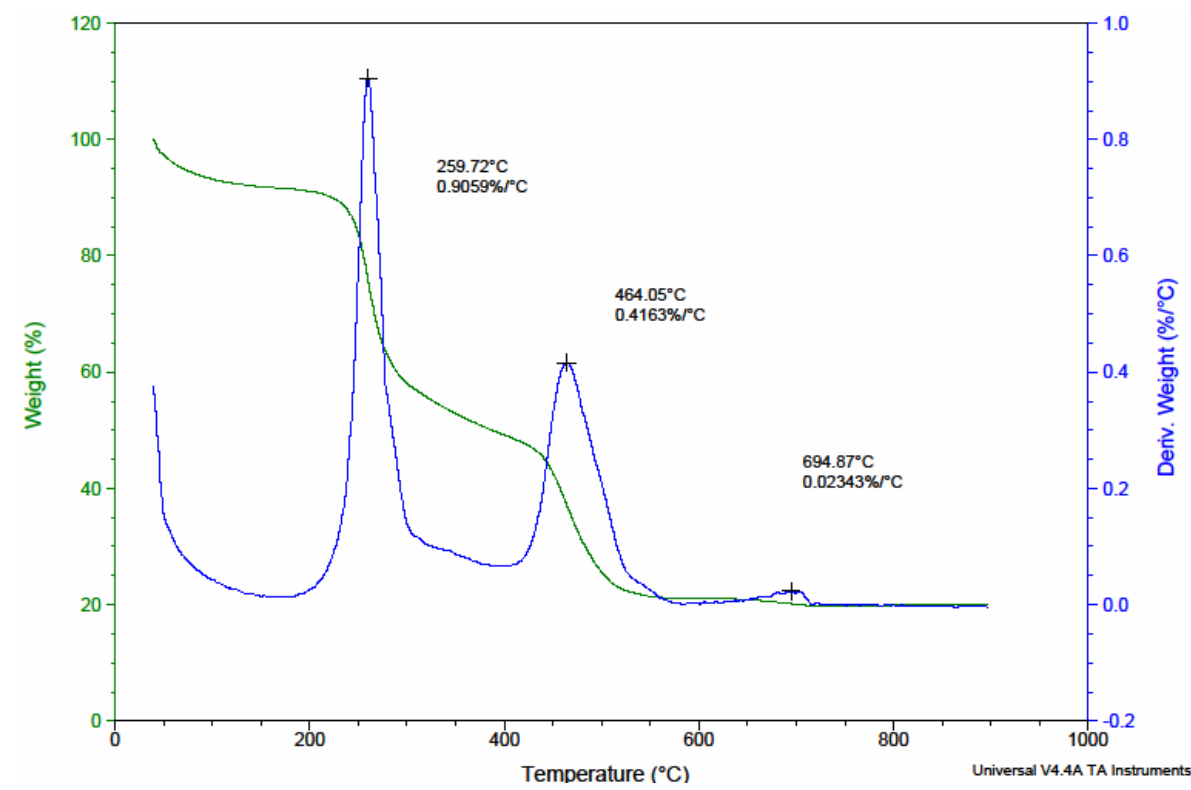

(c)

\section{2. $\mathrm{Zn}^{2+}$ Adsorption Studies}

Prior to the preparation of nano $\mathrm{ZnO}$, it is important to have an idea about the affinity of both native and surface modified chitosan towards zinc metal ions. Hence, we have carried out adsorption of $\mathrm{Zn}^{2+}$ in solution as a preliminary study using all chitosans as adsorbents. The adsorption studies carried out in this work suggested that as compared to another models, Freundlich isotherms showed the best fitting value for the kinetics of $\mathrm{Zn}^{2+}$ on chitosans and the adsorption process is chemical adsorption. Figure 3 shows the Freundlich adsorption isotherms of different chitosans for $\mathrm{Zn}^{2+}$ ion, and Table 3 includes the Freundlich isotherm parameters of different systems. The experimental results clearly revealed that unmodified chitosan generally showed lower affinity towards $\mathrm{Zn}^{2+}$ than modified chitosan [29]. Thus, it is corroborated, that due to surface modification, the affinity of chitosans towards $\mathrm{Zn}^{2+}$ is enhanced owing to the presence of both $\mathrm{COOH}$ and $\mathrm{NH}_{2}$ groups. Among all, CMC1 
showed the enhanced $\mathrm{Zn}^{2+}$ adsorption with increased $\mathrm{K}$ (capacity of the adsorbent for the adsorbate, $\mathrm{mg} / \mathrm{g}$ ) and $\mathrm{n}$ (constant) values. The order of adsorption capacity of the chitosans can be arranged as $\mathrm{CMC} 1>\mathrm{CMC} 4>\mathrm{CMC} 2>\mathrm{CMC} 5>\mathrm{CMC} 6>\mathrm{CTS}>\mathrm{CMC} 3$. Based on this, it is observed that both the concentrations of sodium chloroacetate and isopropyl alcohol are the two major factors that control the adsorption process. The fundamental results indicated that smaller the sodium chloroacetate concentration and higher the isopropyl alcohol concentration, the greater the $\mathrm{Zn}^{2+}$ affinity. If sodium chloroacetate concentration is increased, instead of replacement of $\mathrm{OH}$ by $\mathrm{COOH}$, the $\mathrm{NH}_{2}$ on chitosan surface is replaced by $\mathrm{NHCH}_{3} \mathrm{COONa}$ and, thus, the free $\mathrm{NH}_{2}$ sites are decreased. Hence, the adsorption of $\mathrm{Zn}^{2+}$ is diminished if the sodium chloroacetate concentration is increased.

However, higher concentration of isopropyl alcohol facilitated the adsorption of $\mathrm{Zn}^{2+}$ ions due to smaller water puffing extent during surface modification. When the concentration of isopropyl alcohol is increased, it prevents the aggregation of the particles due to water swelling effect and makes the system more homogeneous. In addition, higher concentration of isopropyl alcohol prevents the hydrolysis reaction during surface modification by increasing the utilization of sodium chloroacetate.

Table 3. Freundlich isotherm parameters for adsorption of $\mathrm{Zn}^{2+}$ by different chitosans.

\begin{tabular}{cccc}
\hline Precursors & $\boldsymbol{R}^{\mathbf{2}}$ & $\begin{array}{c}\text { K (capacity of the adsorbent } \\
\text { for the adsorbate, } \mathbf{~ m g / g )}\end{array}$ & $\boldsymbol{n}$ (constant) \\
\hline CTS & 0.9918 & 9.85 & 1.0040 \\
CMC1 & 0.9547 & 69.78 & 12.9032 \\
CMC2 & 0.9333 & 32.36 & 7.0373 \\
CMC3 & 0.9438 & 5.29 & 2.9551 \\
CMC4 & 0.9556 & 51.17 & 7.8612 \\
CMC5 & 0.9828 & 24.00 & 5.9277 \\
CMC6 & 0.9522 & 20.20 & 6.7843 \\
\hline
\end{tabular}

Figure 3. Adsorption of $\mathrm{Zn}^{2+}$ ions by native and surface modified chitosans.

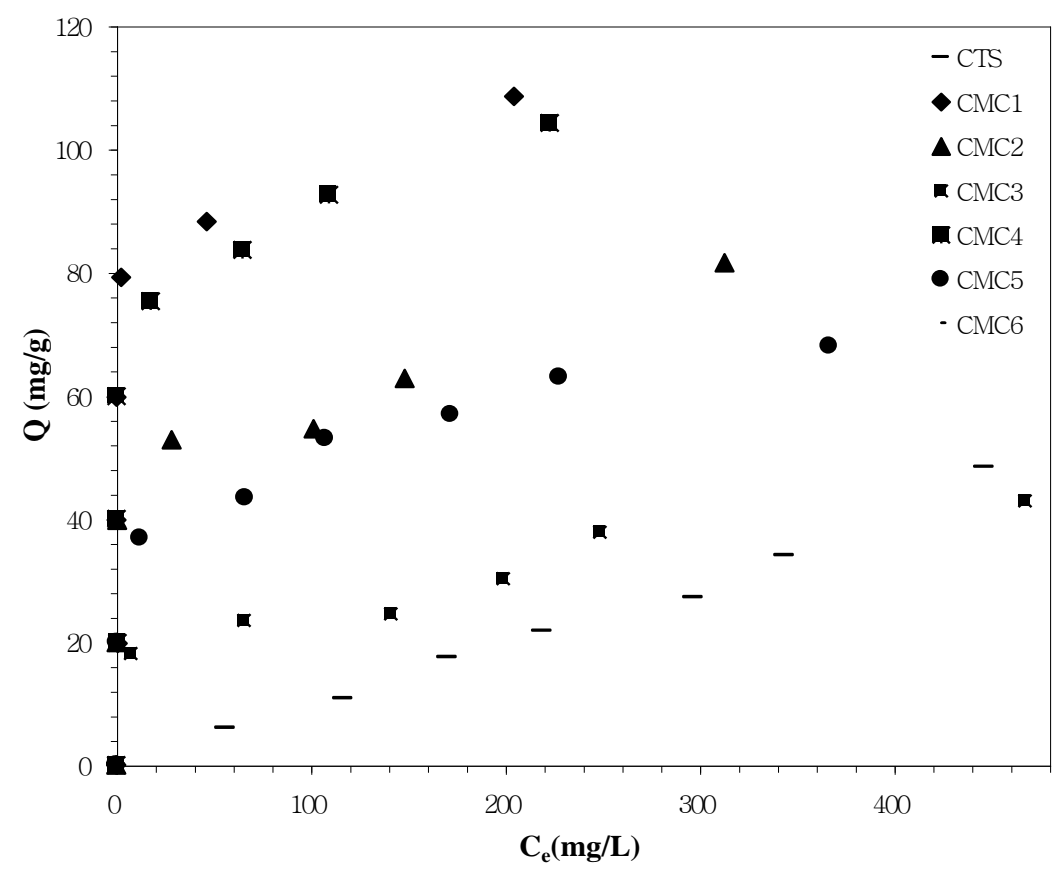




\subsection{Characterization of $\mathrm{ZnO}$}

The facile preparation of nano $\mathrm{ZnO}$ was obtained from the cleavage of various zinc-polysacchraide polymers formed from chitosans and zinc nitrate solution. $\mathrm{ZnO}$ was characterized using XRD, SEM, TEM and BET analyses. The XRD patterns of nano $\mathrm{ZnO}$ at different calcination temperatures using various chitosans as chelating agents are given in Figure 4. The diffraction peaks indicate the nanocrystalline nature and identical to the hexagonal phase with Wurtzite structure. The peaks at angles $(2 \theta)$ around $31^{\circ}, 35^{\circ}, 37^{\circ}, 48^{\circ}, 56^{\circ}, 62^{\circ}, 68^{\circ}$, and $69^{\circ}$ correspond to the reflection from 100 , 002, 101,102, 110, 103, 200 to 112 crystal planes, respectively [30]. The $\mathrm{ZnO}$ crystal structure seemed to be unchanged upon calcination at high temperatures but that the crystal size continually increased [31]. From Figure 4 it is connoted that, when the calcination temperature of zinc-chitosan polymer is low $\left(450{ }^{\circ} \mathrm{C}\right)$, the $\mathrm{XRD}$ patterns of $\mathrm{ZnO}$ obtained from various chitosans are well separated from each other (i.e., large separation in terms of intensity) where as in the case of 650 and $850{ }^{\circ} \mathrm{C}$, they are almost close to each other (i.e., less separation in terms of intensity). The SEM of ZnO nanocrystalline particles obtained by various systems is shown in Figure 5. As seen in Figure 5, almost single phase primary particle in spherical shape with uniform distribution was obtained at low calcination temperature $\left(450{ }^{\circ} \mathrm{C}\right)$ of zinc-chitosan polymer where as in the case of high calcination temperatures particles with various shapes and sizes were obtained. Thus, at high calcination temperature of zinc-chitosan polymer, disordered structural distribution of $\mathrm{ZnO}$ was witnessed and sometimes even structural damage.

Figure 4. XRD patterns of various $\mathrm{ZnO}$ samples.

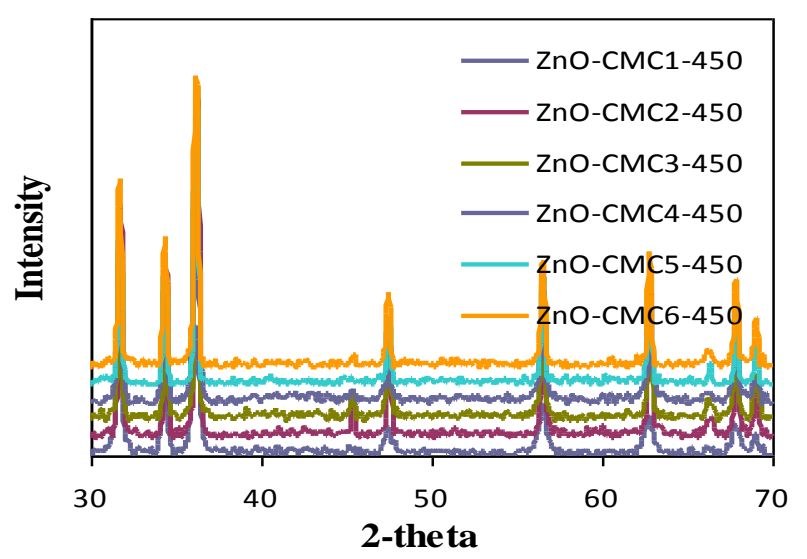

(a)

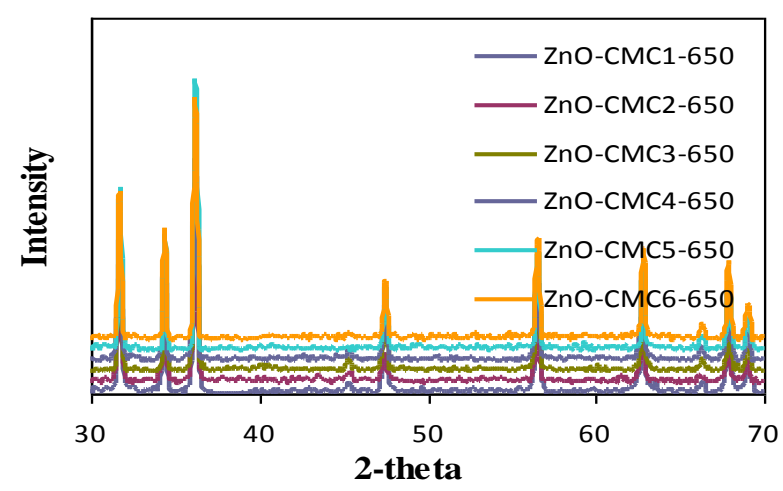

(b) 
Figure 4. Cont.

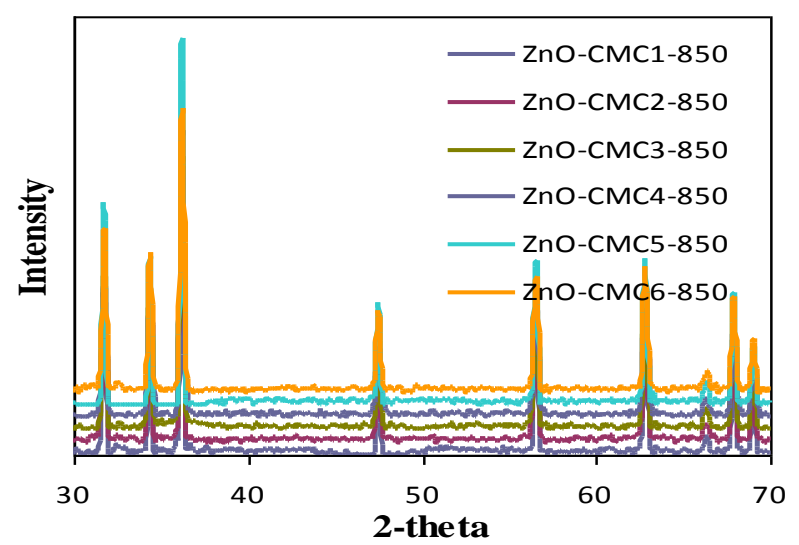

(c)

Figure 5. SEM of (a) ZnO-CTS-450; (b) ZnO-CTS-850; (c) ZnO-CMC1-450; (d) $\mathrm{ZnO}-\mathrm{CMC1}-850$; (e) ZnO-CMC4-450; and (f) ZnO-CMC4-850.
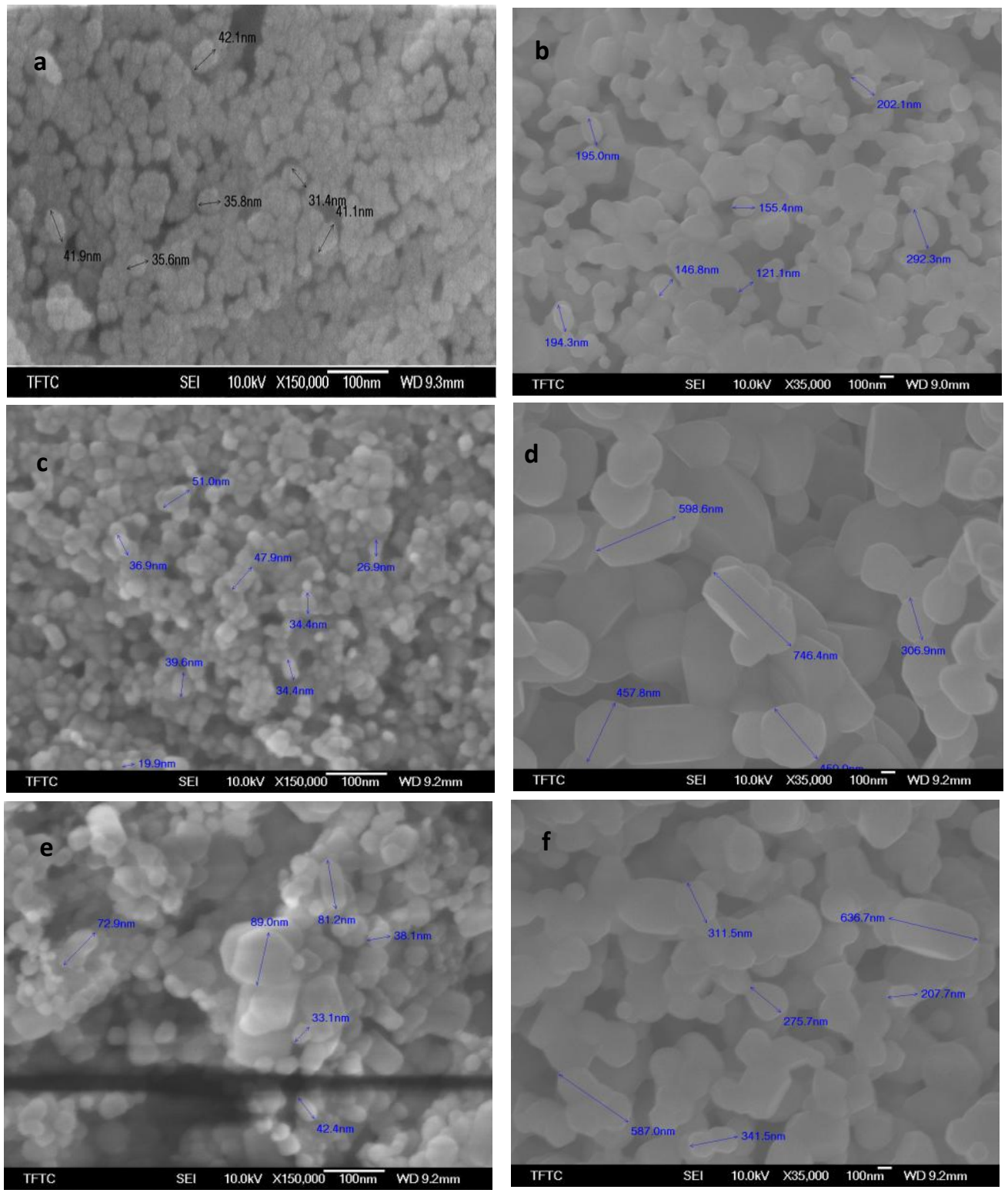
The particle size of various $\mathrm{ZnO}$ obtained is given in Table 4. From Table 4, it is clear that as the calcination temperature of zinc-chitosan polymer increased, the particle size of obtained $\mathrm{ZnO}$ also increased. This clearly explained that nano $\mathrm{ZnO}$ with same crystal type but different particle size can be obtained by varying the calcination temperature [32]. The surface areas are found to be decreased while crystal sizes of the nanoparticles held a certain degree of agglomeration as calcination temperatures gradually increased [31]. Thus, at higher calcination temperatures, the agglomeration of $\mathrm{ZnO}$ nanoparticles became extremely serious and hence the particle size increased. This may be explained as sample effects results from two main effects: (i) the particle-size broadening which results from the finite extent and particular morphology of the coherently diffracting domains within the grains; and (ii) the microstrain broadening, which results from local variations of the d-spacing produced by nonuniform crystalline stresses.

Table 4. Particle size of $\mathrm{ZnO}$ prepared at different calcination temperatures of Zn-chitosan polymers.

\begin{tabular}{cccc}
\hline \multirow{2}{*}{ ZnO samples } & \multicolumn{3}{c}{ Particle size of $\mathbf{Z n O}(\mathbf{n m})$} \\
\cline { 2 - 4 } & $\mathbf{4 5 0}{ }^{\circ} \mathbf{C}$ & $\mathbf{6 5 0}^{\circ} \mathbf{C}$ & $\mathbf{8 5 0}{ }^{\circ} \mathbf{C}$ \\
\hline ZnO-CTS & $31-42$ & $74-193$ & $121-292$ \\
ZnO-CMC1 & $19-54$ & $91-220$ & $306-746$ \\
ZnO-CMC2 & $59-107$ & $72-198$ & $300-835$ \\
ZnO-CMC3 & $43-124$ & $135-519$ & $580-584$ \\
ZnO-CMC4 & $26-69$ & $65-683$ & $207-636$ \\
ZnO-CMC5 & $32-70$ & $67-380$ & $226-1069$ \\
ZnO-CMC6 & 33.89 & $96-211$ & $237-345$ \\
\hline
\end{tabular}

The size and morphology of $\mathrm{ZnO}$ particles analyzed by TEM is represented in Figure 6. This also revealed the uniform size and shape distribution of nano $\mathrm{ZnO}$ obtained at low calcination temperatures of zinc-chitosan polymer.

Figure6. TEM of (a) ZnO-CMC1-450; (b) ZnO-CMC1-650; and (c) ZnO-CMC1-850.

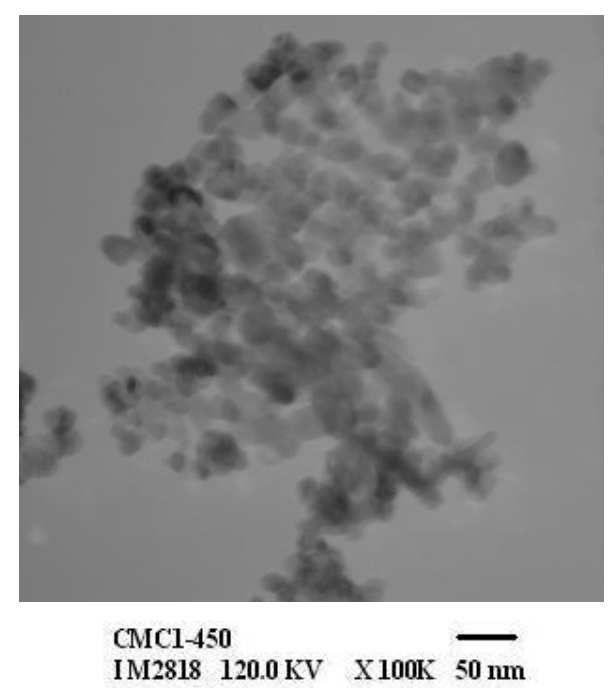

(a)

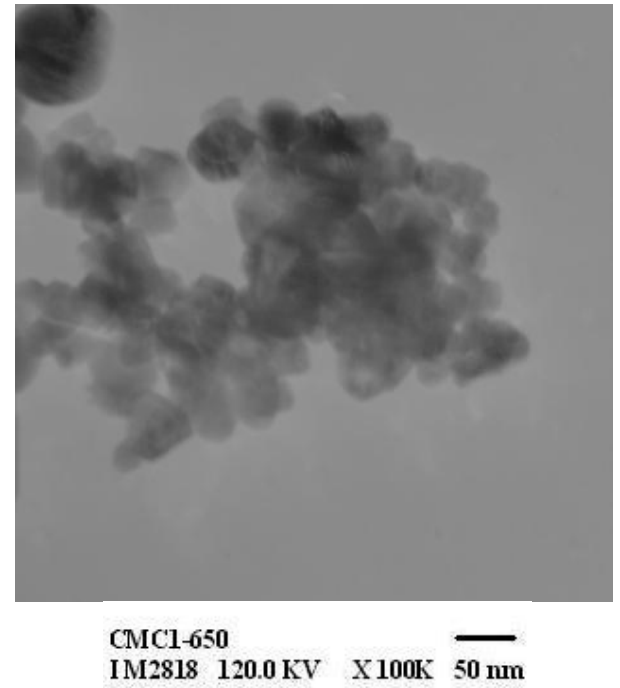

(b) 
Figure 6. Cont.

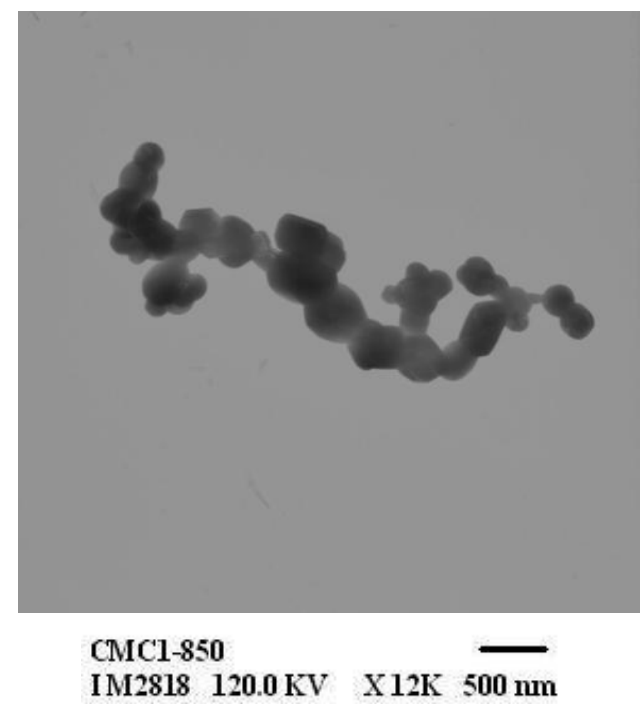

(c)

The hydration ratio [33] can also affect the hydrolysis and condensation rate of the $\mathrm{Zn}$ precursor in solution, as evidenced in the case of $75 \%$ and $50 \%$ isopropyl alcohol systems, by which $\mathrm{ZnO}$ can nucleate and grow into distinct particle morphology. The experimental data showed that varying the synthetic conditions, significantly affected the specific surface area and pore size distribution of obtained $\mathrm{ZnO}$ as shown in Table 5.

Table 5. Surface area and pore size of different $\mathrm{ZnO}$ samples prepared.

\begin{tabular}{ccc}
\hline Samples & BET surface area $\left(\mathbf{m}^{2} / \mathbf{g}\right)$ & Average pore diameter $(\mathbf{n m})$ \\
\hline ZnO-CTS-450 & 23.7664 & 9.70 \\
ZnO-CMC1-450 & 15.4485 & 221.40 \\
ZnO-CMC2-450 & 4.7763 & 106.29 \\
ZnO-CMC3-450 & 4.5767 & 161.62 \\
ZnO-CMC4-450 & 14.1519 & 212.03 \\
ZnO-CMC5-450 & 6.0641 & 119.69 \\
ZnO-CMC6-450 & 6.0966 & 131.10 \\
ZnO-CTS-650 & 11.9273 & 6.97 \\
ZnO-CMC1-650 & 5.8813 & 160.49 \\
ZnO-CMC2-650 & 2.9608 & 108.93 \\
ZnO-CMC5-650 & 2.3485 & 8.96 \\
ZnO-CMC6-650 & 3.1625 & 10.59 \\
\hline
\end{tabular}

As discussed earlier, unmodified chitosan showed low affinity for $\mathrm{Zn}^{2+}$ ions which necessarily initiated the surface modification of chitosan for the enhanced affinity for $\mathrm{Zn}^{2+}$ ions. Surface modification of chitosans perhaps eases the formation of zinc-chitosan polymers. However, quite interestingly, nano $\mathrm{ZnO}$ obtained from cleavage of zinc-unmodified chitosan polymer possessed a larger surface area and an exceptionally smaller pore size. However, still surface modification is indispensable for the effective interaction of chitosans with zinc ions. Among surface modified chitosans, $\mathrm{ZnO}$ obtained from cleavage of zinc-CMC1 had a significantly higher surface area and larger pore size than those of others. The findings of this work can be concluded as different 
parameters affect the efficiency of zinc-modified chitosan polymers to produce nano $\mathrm{ZnO}$ and among which $1.5 \mathrm{M}$ sodium chloroacetate, $75 \%$ isopropyl alcohol and calcination at $450{ }^{\circ} \mathrm{C}$ are the optimized parameters to obtain nano $\mathrm{ZnO}$ with enhanced surface area.

\section{Conclusions}

A facile preparation of nano $\mathrm{ZnO}$ was reported in this work. Native and surface modified chitosans were used as both chelating and structure directing agents. Upon surface modification (prior to $\mathrm{ZnO}$ synthesis), sodium chloroacetate and isopropyl alcohol were the major factors that controlled the stability and surface property of modified chitosans. These modified and unmodified chitosans were characterized using FT-IR and TGA analyses. In order to understand the interaction of these polysachharides with zinc ions, adsorption experiments were carried out as preliminary studies and Freundlich adsorption isotherms were reported. It was observed that surface modified chitosans showed enhanced adsorption towards zinc ions. Reaction of these modified and unmodified chitosans with zinc salt was carried out to produce zinc-organic polymer. Finally upon calcination, the cleavage of these polymer produced nano $\mathrm{ZnO}$. The obtained $\mathrm{ZnO}$ was characterized using XRD, FT-IR, SEM, TEM, and BET analysis. The effect of different calcination temperature was also studied. This study indeed suggested that a cost effective and viable technology for effective preparation of nano $\mathrm{ZnO}$ could be developed using easily available, familiar, and eco-friendly chitosans.

\section{Acknowledgment}

We thank the National Central University and National Science Council (NSC), Grant No.: NSC99-2221-E-008-025-MY3, Taiwan, Republic of China (ROC), for financial support.

\section{Conflicts of Interest}

The authors declare no conflict of interest.

\section{References}

1. Nakayama, V.; Pauzauskie, P.J.; Radenovic, A.; Onorato, R.M.; Saykally, R.J.; Liphardt, J.; Yang, P.D. Tunable nanowire nonlinear optical probe. Nature 2007, 447, 1098-1101.

2. Tomchenko, A.A.; Harmer, G.P.; Marquis, B.T.; Allen, J.W. Semiconducting metal oxide sensor array for the selective detection of combustion gases. Sens. Actuators B 2003, 93, 126-134.

3. Chen, S.H.; Nickel, U.; Ren, X.M. Fluorescence of $\mathrm{ZnO}$ ultrafine particles quenched by naphthothiacarbocyanine dye in ethanol: the effect of water. J. Colloid Interface Sci. 1995, 176, 286-292.

4. Marcì, G.; Augugliaro, V.; López-Muñoz, M.J.; Martín, C.; Palmisano, L.; Rives, V.; Schiavello, M.; Tilley, R.J.D.; Venezia, A.M. Preparation characterization and photocatalytic activity of polycrystalline $\mathrm{ZnO} / \mathrm{TiO}_{2}$ systems. 2. Surface, bulk characterization, and 4-nitrophenol photodegradation in liquid-solid regime. J. Phys. Chem. B 2001, 105, 1033-1040.

5. Ghosh, A.; Das, S.K.; Biswas, J.R.; Tripathi, H.S.; Banerjee, G. The effect of ZnO addition on the densification and properties of magnesium aluminate spinel. Ceram. Int. 2000, 26, 605-608. 
6. Wu, Y.L.; Tok, A.I.Y.; Boey, F.Y.C.; Zeng, X.T.; Zhang, X.H. Surface modification of ZnO nanocrystals. Appl. Surf. Sci. 2007, 253, 5473-5479.

7. Bae, S.Y.; Seo, H.W.; Park, J. Vertically aligned sulfur-doped $\mathrm{ZnO}$ nanowires synthesized via chemical vapor deposition. J. Phys. Chem. B 2004, 108, 5206-5210.

8. Chang, P.C.; Fan, Z.Y.; Wang, D.W.; Tseng, W.Y.; Chiou, W.A.; Hong, J.; Lu, J.G. ZnO nanowires synthesized by vapor trapping CVD method. Chem. Mater. 2004, 16, 5133-5137.

9. Choi, K.S.; Lichtenegger, H.C.; Stucky, G.D.; McFarland, E.W. Electrochemical synthesis of nanostructured $\mathrm{ZnO}$ films utilizing self-assembly of surfactant molecules at solid-liquid interfaces. J. Am. Chem. Soc. 2002, 124, 12402-12403.

10. Li, M.; Zhai, J.; Liu, H.; Song, Y.L.; Jiang, L.; Zhu, D.B. Electrochemical deposition of conductive superhydrophobic zinc oxide thin films. J. Phys. Chem. B 2003, 107, 9954-9957.

11. Wang, Y.C.; Leu, I.C.; Hon, M.H. Effect of colloid characteristics on the fabrication of $\mathrm{ZnO}$ nanowire arrays by electrophoretic deposition. J. Mater. Chem. 2002, 12, 2439-2444.

12. Gao, X.P.; Zheng, Z.F.; Zhu, H.Y.; Pan, G.L.; Bao, J.L.; Wu, F.; Song, D.Y. Rotor-like ZnO by epitaxial growth under hydrothermal conditions. Chem. Commun. 2004, 12, 1428-1429.

13. Kuo, C.; Kuo, T.J.; Huang, M.H. Hydrothermal synthesis of $\mathrm{ZnO}$ microspheres and hexagonal microrods with sheetlike and platelike nanostructures. J. Phys. Chem. B 2005, 109, 20115-20121.

14. Cheng, B.; Samulski, E.T. Hydrothermal synthesis of one-dimensional $\mathrm{ZnO}$ nanostructures with different aspect ratios. Chem. Commun. 2004, 8, 986-987.

15. Tokumoto, M.S.; Pulcinelli, S.H.; Santilli, C.V.; Briois, V. Catalysis and temperature dependence on the formation of $\mathrm{ZnO}$ nanoparticles and of Zinc acetate derivatives prepared by the sol-gel route. J. Phys. Chem. B 2003, 107, 568-574.

16. Werde, K.V.; Mondelaers, D.; Vanholand, G.; Nelis, D.; Van Bael, M.K.; Mullens, J.; Van Poucke, L.C. Thermal decomposition of the ammonium zinc acetate citrate precursor for aqueous chemical solution deposition of ZnO. J. Mater. Sci. 2002, 37, 81-88.

17. Abdullah, M.; Okuyama, K. Zinc oxide nanoparticles prepared by a simple heating: Effect of polymer addition and polymer absence on the morphology. PROC ITB Eng. Sci. 2004, 36, 141-153.

18. Shen, X.; Liang, Y.; Zhai, Y.; Ning, Z. Shape-controllable synthesis of ultrafine ZnO powders of fifferent morphologies. J. Mater. Sci. Technol. 2013, 29, 44-48.

19. Tian, Y.; Li, J.; Xiong, H.; Dai, J. Controlled synthesis of ZnO hollow microspheres via precursor-template method and its gas sensing property. Appl. Surf. Sci. 2012, 258, 8431-8438.

20. Pant, H.R.; Park, C.H.; Pokharel, P.; Tijing, L.D.; Lee, D.S.; Kim, C.S. ZnO micro-flowers assembled on reduced graphene sheets with high photocatalytic activity for removal of pollutants. Powder Technol. 2013, 235, 853-858.

21. Pant, H.R.; Pant, B.; Sharma, R.; Amarjargal, A.; Kim, H.J.; Park, C.H.; Tijing, L.D.; Kima, C.S. Antibacterial and photocatalytic properties of $\mathrm{Ag} / \mathrm{TiO}_{2} / \mathrm{ZnO}$ nano-flowers prepared by facile one-pot hydrothermal process. Ceram. Int. 2013, 39, 1503-1510.

22. Odunola, O.A. Spectroscopic and magnetic properties of $\mathrm{Zn}(\mathrm{II}), \mathrm{Cd}(\mathrm{II})$ and $\mathrm{Hg}(\mathrm{II})$ carboxylates. Synth. React. Inorg. Met. Org. Chem. 1993, 23, 1241-1249.

23. Tang, L.-G.; Hon, D.N.-S. Chelation of chitosan derivatives with zinc ions. II. Association complexes of $\mathrm{Zn}^{2+}$ onto O,N-Carboxymethyl chitosan. J. Appl. Polym. Sci. 2001, 79, 1476-1485. 
24. Farag, S.; Kareem, S.S.A.A. Different natural biomasses for lead cation removal. Carbohyd. Polym. 2009, 78, 263-267.

25. Mourya, V.K.; Inamdar, N.N. Chitosan-modifications and applications: Opportunities galore. React. Function. Polym. 2008, 68, 1013-1051.

26. Tang, L.-G.; Hon, D.N.-S. Chelation of chitosan derivatives with zinc ions. II. Association complexes of $\mathrm{Zn}^{2+}$ onto O,N-carboxymethyl chitosan. J. Appl. Polym. Sci. 2001, 79, 1476-1485.

27. Zhao, X.; Kato, K.; Fukumoto, Y.; Nakamae, K. Synthesis of bioadhesive hydrogels from chitin derivatives. Int. J. Adhes. Adhes. 2001, 21, 227-232.

28. Desai, K.; Kit, K.; Li, J.; Zivanovic, S. Morphological and surface properties of electrospun chitosan nanofibers. Biomacromolecules 2008, 9, 1000-1006.

29. Becker, T.; Schlaak, M.; Strasdeit, H. Adsorption of nickel(II), zinc(II) and cadmium(II) by new chitosan derivatives. React. Funct. Polym. 2000, 44, 289-298.

30. Gu, F.; Wang, S.F.; Lu, M.K.; Zhou, G.J.; Xu, D.; Yuan, D.R. Structure evaluation and highly enhanced luminescence of $\mathrm{Dy}^{3+}$-doped $\mathrm{ZnO}$ nanocrystals by $\mathrm{Li}^{+}$doping via combustion method. Langmuir 2004, 20, 3528-3531.

31. Ye, J.; Zhou, R.; Zheng, C.; Sun, Q.; Lv, Y.; Li, C.; Hou, X. Size-controllable synthesis of spherical $\mathrm{ZnO}$ nanoparticles: Size- and concentration-dependent resonant light scattering. Microchem. J. 2012, 100, 61-65.

32. Wang, Y.; Zhang, C.; Bi, S.; Luo, G. Preparation of $\mathrm{ZnO}$ nanoparticles using the direct precipitation method in a membrane dispersion micro-structured reactor. Powder Tech. 2010, 202, 130-136.

33. Lee, S.; Jeong, S.; Kim, D.; Hwang, S.; Jeon, M.; Moon, J. ZnO nanoparticles with controlled shapes and sizes prepared using a simple polyol synthesis. Superlattice Microstruct. 2008, 43, 330-339.

(C) 2013 by the authors; licensee MDPI, Basel, Switzerland. This article is an open access article distributed under the terms and conditions of the Creative Commons Attribution license (http://creativecommons.org/licenses/by/3.0/). 